\title{
WHEN POLICY IS NOT ENOUGH: PROSPECTS AND CHALLENGES OF ARTISANAL AND SMALL-SCALE MINING IN SOUTH AFRICA
}

\author{
Pontsho Ledwaba* \\ Kgothatso Nhlengetwa**
}

\begin{abstract}
As in most countries, artisanal and small-scale mining (ASM) activities are recognised in South Africa. ASM activities first became part of the socioeconomic development agenda of the country in 1994 after the change in government. ASM was identified as an important platform where disadvantaged South Africans can participate and benefit from the mining industry. This is because of the potential benefits that government has sought to support the sub-sector. In the past two decades, several programmes and initiatives have been introduced to promote and advance the sub-sector. In the majority of cases, these interventions failed to facilitate the development of the sub-sector and, to a large extent, its contribution to local economies. This is attributed to a myriad of challenges still facing the sub-sector today. The objective of this paper is to map all the critical developments that took place in the sub-sector in an attempt to develop and deploy appropriate assistance to the sub-sector. The paper assesses their impact, if any, on the growth of ASM in South Africa. With the country into its second decade of democracy, it has become crucial to reflect on past experiences and use them as learning curve to create a new thriving economy.
\end{abstract}

Keywords: artisanal and small scale mining (ASM), timeline, poverty alleviation, sustainable development, South African mining policy.

doi: http://dx.doi.org/10.4314/jsdlp.v6i2.2

* Corresponding author, Pontsho Ledwaba, Research Engineer, Small-Scale Mining and Beneficiation (SSMB) Division, MINTEK, 200 Malibongwe Drive Randburg, 2125, Republic of South Africa, Tel: +27 11709 4337, email: pontshol@ mintek.co.za.

** Ph.D Candidate, School of Geosciences, University of the Witwatersrand, Johannesburg, Private Bag 3, WITS, 2050, Republic of South Africa, Tel: +27 11717 6623, E-mail: kgothatso.nhlengetwa@students. wits.ac.za. 


\section{INTRODUCTION}

South Africa is recognised as a global leader in mining. With an estimated in-situ mineral base of USS2.5trillion, ${ }^{1}$ it has established itself particularly among its African peers as an expert in the mining industry. The mining industry in South Africa is dominated by (large) transnational mining houses as opposed to local companies - 90 per cent of the mining houses are largescale. ${ }^{2}$ Much as the industry is contributing significantly to economic growth and social development (i.e. employment of locals); there is a growing need for locals to have direct access to the industry and to benefit from the country's mineral riches.

In the advent of democracy, the new government identified a "new" form of mining which had the potential to redress some of the legacies left by the apartheid regime. Before 1994, people of colour, women, junior and smallscale mining enterprises were excluded from participating in the minerals and mining economy. To address this challenge, government identified Artisanal and Small-Scale Mining (ASM) as a vehicle for social and economic development, particularly for disadvantaged communities that were excluded from participating in the national mining economy. ${ }^{3}$ ASM offered alternative economic opportunities for the majority that reside in rural parts of the country in severe poverty. It was in 1994, following the change in government, that the ASM sub-sector was formally recognised in South Africa.

This recognition saw the main legislative framework endorsing all forms of mining, including ASM. The inclusion of ASM in the Minerals and Petroleum Resource and Development Act (MPRDA) led to the establishment of support structures directed at the development of the sub-sector. ${ }^{4}$ The Department of Mineral Resources (DMR), as the main administrator of the mining industry, introduced several initiatives in an attempt to advance the sub-sector. Most of these produced mixed results, especially if measured against the policy requirements as initially outlined in the 1998 Minerals and Mining Policy (MMP) for South Africa.

With the intention of encouraging and facilitating the sustainable development of ASM in the country so as to contribute positively to national,

1 Address by Mr David Msiza (Chief Inspector of Mines), 09 June 2015.

2 Landu, L. 2014. Junior Mining in South Africa, (Fossil Fuel Foundation Conference, 27 June 2014).

3 Minerals and Mining Policy for South Africa 1998.

4 Minerals and Petroleum Resource Development Act No. 28, 2002. 
provincial and local economies, the DMR and associated institutions met a myriad of challenges. This was not anticipated, given the reputation of South Africa as a mining giant. For a country that is well-respected for its developed policies and legislative framework and also its strong position in the mining industry, the progress made, as far as the development of the ASM sub-sector is concerned, is rather disappointing. As such, there is a need to critically analyse the impact of these "programmes or initiatives" on the ASM subsector so as to address a number of unanswered questions. Some of these questions relate to South Africa being on the right path in terms of the development of ASM and also the future of ASM as a potential poverty-reduction avenue in the country.

This paper proceeds to map all the critical developments that took place in the sub-sector and their impact, if any, on the growth of the sector. Briefly discussed in the paper are the views of the African Mining Vision (AMV). AMV is a home-grown vision which supports the development of ASM and, hence, appreciates the potential positive contribution that ASM can make to local and national economies. The Vision provides guiding principles for the development of ASM across the African continent taking into account not only its potential, but also the many barriers that governments need to overcome in order to reap the full benefits of ASM.

\section{ASM IN SOUTH AFRICA}

ASM in South Africa is defined as a "mining activity employing less than 50 people, and has annual turnover of less than R10 million with fixed and moveable assets of less than R15 million." "This formal definition is adopted from the National Small Business Act which is legislative framework enacted to promote Small, Medium and Micro Enterprises (SMMEs) development in the country. ${ }^{6}$ This means that ASM is regarded as a type of a small business. The Act essentially places ASM (activities) on a comparative level with other small businesses in other economic sectors such as agriculture, manufacturing, construction, retail, commercial and allied services sectors.

Among the relevant issues raised during the formal recognition of ASM was the definition of the sub-sector. To date, it remains one of the critical

5 Scott, R., Rockey, N., and Hudson, R, The Status of Small-Scale Mining in South Africa - A Preliminary Study. (Minerals and Energy Policy Centre and The Marketing Shop 1998) 2-3; Mutemeri, N. and Petersen, F.W. Small-Scale Mining in South Africa: Past, Present and Future (Natural Resource Forum, 2002) 287-88.

6 National Small Business Act No. 102, 1996. 
gaps. The MMP in 1998 called for clarification of small-scale and artisanal mining. In South Africa, these two forms of mining are not clearly distinguished and, hence, programmes or initiatives introduced tend to undermine artisanal mining, which is not well understood. ${ }^{7}$ Much as the Act classifies ASM according to three different forms, namely micro, very small and small; the characteristics and hence peculiar needs of each form are not well comprehended. This definition has been criticised by multiple stakeholders; hence, different characteristics are usually added to draw a more convincing picture of ASM. A broader definition of ASM includes mining operations which are unregulated; they range from activities conducted by individuals (i.e., diamond diggers) to junior operations; the majority of activities are poverty-driven, with a few business orientated; they can be permanent or seasonal in nature; they are technologically backwards using very little, if any, mechanisation; the sub-sector is informal and carried out illegally; it is mainly unauthorised and undercapitalised; and it is known for the low standards of health, safety and environment. ${ }^{8}$ Notably, all these characteristics are a summary of the many issues or challenges faced by the sub-sector.

While all these challenges are noted, there are social and economic benefits to be extracted from ASM activities. ASM has proven to hold significant economic potential particularly for developing countries. Globally, ASM employs between 20 and 30 million people; this compares to 13 million people in 1999. In Africa, an estimated 8 million people are employed by the sector; against 3 and 3.7 million in 1999. ${ }^{9}$ According to Buxton, ASM employs ten times more people than their large-scale counterparts. Furthermore, the African Mining Vision (AMV) reports that between 15 and 20 per cent of the world's non-fuel minerals, 18 per cent of Africa's gold, and almost all African

7 Debrah, A. A, Watson, I and Quansah, D.P.O, "Drawing Parallels between Ghana's and South Africa's ASM Sectors: Lessons Learnt and Ways Forward" (Mining, Environment and Society Conference 2013), The Southern Institute of Mining and Metallurgy (SAIMM)Vol.114, 917.

8 Minerals and Mining Policy of South Africa, 1998; B Dreschler, Small Scale Mining and Sustainable Development within SADC Region. Minerals Mining and Sustainable Development (MMDS) 2001, Report no. 84, 92-100.; Debrah, A.A, Watson, I and Quansah, D.P.O (n 7) 917-918.

9 International Labour Organisation (ILO), Social and Labour Issues in Small-scale Mines (Geneva, Switzerland 1999); A Benkenstein, "Artisanal and Small Scale Mining in Africa: Opportunities and Challenges" (2012) <www.saiia.org.za/ opinion-analysis/artisanal-and-small-scale-mining-in-africa-opportunities-andchallenges $>$ accessed 10 October 2015; Buxton A, Responding to the Challenge of Artisanal and Small-Scale Mining. How Can Knowledge Networks Help? (IIED 2013) < http://pubs.iied.org/pdfs/16532IIED.pdf> accessed 10 October 2015. 
gemstones, except diamonds are produced by ASM. ${ }^{10}$ Undoubtedly, ASM has immense potential which could potentially contribute to national and local economies of resources-rich countries in Africa.

In the case of South Africa, it is estimated that ASM employs between 10,000 and 30,000 people. ${ }^{11}$ Compared to the total number of people employed by the mining fraternity (500,000 direct jobs), ${ }^{12}$ ASM accounts for a paltry 2 to 6 per cent. There is a dearth of conclusive data with respect to the exact number of people employed by the sub-sector, and those that benefit indirectly from the sub-sector. It is speculated that the number of ASM participants gradually increased after the enactment of MPRDA. However, due to bureaucratic requirements and impractical policies and laws a decline is evident in legal ASM participants. It is not yet established if the data includes either undocumented operations or covers only those operations within the legal framework.

Research on ASM in South Africa is limited and has not been used to substantiate, with science-based evidence, the contribution of ASM to socioeconomic indicators (i.e. national GDP, country's mineral production, local economies, local employment, rural development, etc.). A detailed study conducted by the Minerals and Energy Policy Centre (MEPC) in October 1998 is one of the few available pieces of research. This evidence followed the release of the Green Paper on Minerals and Mining Policy in February 1998. The MEPC study aimed at understanding the ASM challenges (access to mineral rights, access to markets, access to funding, training and skills, institutional support, etc.).

From a socio-economic perspective, the study revealed a total of 550 ASM operations (i.e., mines employing less than 50 people) which employed 3,783 people (compared to 546,164 employed by the whole industry). ${ }^{13} \mathrm{~A}$ more recent report by the Mine Health and Safety Council estimates the number of registered ASM operations at 1,030. ${ }^{14}$ This somewhat correlates with data presented by Ledwaba where the number of mining permits issued between

10 African Mining Vision, 2009.

11 Mutemeri, N. and Petersen, F. W (n 5) 287-288; Limpitlaw D and Hoadley M, The Artisanal and Small-Scale Mining Sector and Sustainable Livelihoods (School of Mining Engineering, University of the Witwatersrand 2004) 1.

12 Chamber of Mines, Facts and figures 2013/2014.

13 Scott, R, Rockey, N, and Hudson, R, The Status of Small-Scale Mining in South Africa - A Preliminary Study. (Minerals and Energy Policy Centre and The Marketing Shop October 1998) 58-77.

14 Mine Health and Safety Council work on the small-scale mining project, 2004. 
2004 and 2010 equated to $1,300 .{ }^{15}$ Evidently, the sector has grown considerably since 1994 with reported figures now exceeding 10,000. Observably, the numbers are still very low compared to countries with relatively similar mineral endowment.

Minerals exploited by ASMs range from precious minerals to industrial and construction minerals. The majority are known to exploit industrial minerals (IM) (over 70 per cent). ${ }^{16}$ The challenges facing the sub-sector include, access to mineral rights and land tenure, lack of financial opportunities, limited pathways to mineral markets, compliance (health, safety and environment) and technology and skills. ${ }^{17}$

With these many ASM challenges in mind, the next step was to understand the nature and needs of ASM across the entire spectrum. Subsequently, the baseline information was used to inform policy direction and legislative framework which ultimately guided implementation. This was followed by implementation structures embedded with the responsibility of carrying out the action plans and strategies. Furthermore, appropriate resources and capacity were made available for implementation. Similar procedures were adopted in South Africa; however, the depth at which each stage was conducted is questionable given the unsatisfactory performance of the sub-sector now that the country is in its second decade of democracy.

\section{TIMELINE OF ASM IN SOUTH AFRICA}

The mining industry in South Africa underwent multiple changes over the past two decades. As part of rebuilding the future of the industry from Apartheid discriminatory laws and practices, past legislation was repealed and a new one was enacted which recognised all forms of mining, whether small or large. As already noted, ASM was only officially recognised after 1994. The status of the sub-sector prior to 1994 is not taken into account despite evidence that ASM activities existed long before the emergence of modern, large-scale mining industries. ${ }^{18}$ Figure 1 illustrates the major developments that took place in a bid to support and develop the ASM sector in South Africa.

15 P Ledwaba, The Status of Artisanal and Small-scale Mining in South Africa: Tracking Progress. Presented at the Mining, Environment and Society Conference, SAIMM 2015) 112-113.

16 Department of Mineral Resources, "Nurturing Junior Miners of the Future: A Strategic Framework to Facilitate the Growth of Small-Scale Mining Sector in South Africa" December 2011.

17 ibid.

18 Ledwaba (n 15) 111. 


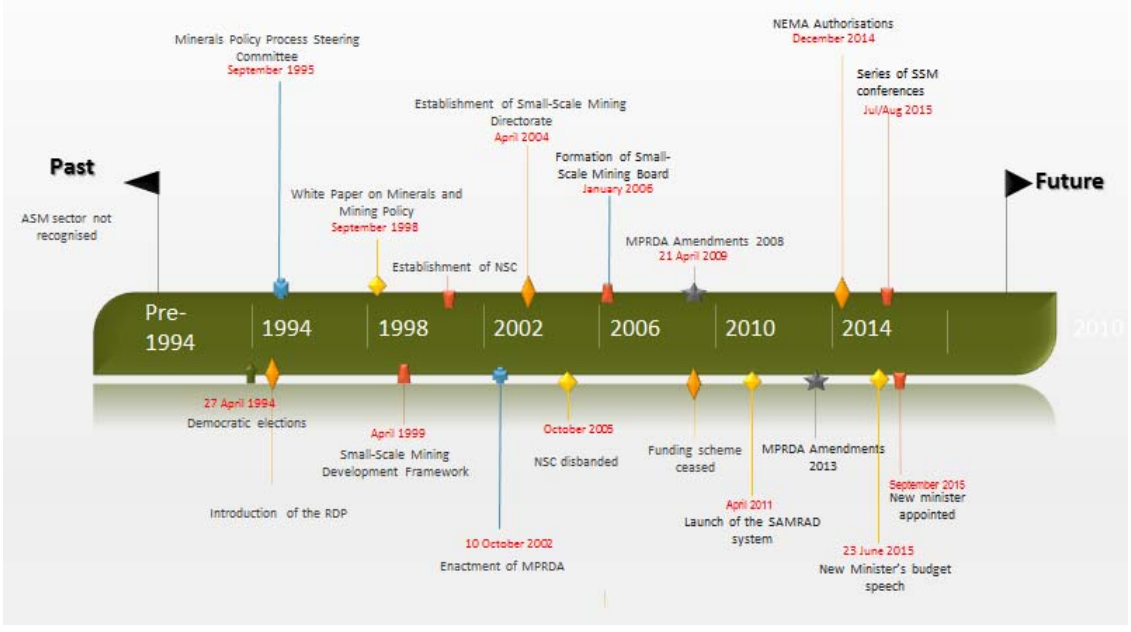

Figure 1. A Timeline for ASM in South Africa.

Following the democratic elections in April 1994, the Reconstruction and Development Programme (RDP) which is a policy framework aimed at eradicating past injustices inherited from the Apartheid government was introduced. As an integrated and coherent socio-economic policy, the RDP strove to achieve the following key objectives: meeting basic (societal) needs, developing human resources, building the economy, and democratising the state and society. ${ }^{19}$ As part of building the economy, the RDP urged government to consider ways and means of encouraging small-scale mining, and to further enhance opportunities for participation through support, including financial and technical aid and access to mineral rights. It was through this recommendation that the Minerals Policy Process Steering Committee was established in September 1995. The committee was given a mandate to conduct an extensive consultative process with all relevant parties for the preparation of new Minerals and Mining Policy of South Africa. The Green Paper on Minerals and Mining Policy was based on the inputs from the committee. After going through reviews, comments and amendments, the White Paper on Minerals and Mining Policy of South Africa was approved in September 1998.

The first official mention of small-scale mining in South Africa is in the White Paper - containing dedicated chapter on small-scale mining. The

19 Government Gazette, White Paper on Reconstruction and Development Programme $(R D P)$, Republic of South Africa, Cape Town, 15 November 1994. 
intention of government in relation to ASM, as mentioned in the White Paper, is to "encourage and facilitate the sustainable development of small-scale mining in order to ensure the optimal exploitation of small mineral deposits and to enable this sector to make a positive contribution to the national, provincial and local economies." 20 The policy makes clear the potential role that ASM could play specifically in mineral production, economic growth and income redistribution. It was through these envisaged benefits that government committed itself to facilitating the development of ASM into a sustainable, profitable, healthy, safe and environmental friendly sub-sector. Included in the policy are the challenges to be mitigated for the sub-sector to flourish. They are, inter alia, access to information, access to mineral rights, technical assistance, training and skills, access to finance (capital), mining regulations and administrative requirements, impacts on environment, health and safety standards, and institutional support.

With the challenges and opportunities noted, the National Small-Scale Mining Development Framework was launched in April 1999. ${ }^{21}$ Its intended role was to provide small-scale mines with the required technical and financial assistance to become viable projects qualifying for access to capital for mine development. Funding remained a challenge for the majority even though they had bankable documents required by potential financers. For some reason, the negative perceptions about the sub-sector prevailed over what could be economically viable business ventures.

Aware of these challenges, government established the National Steering Committee (NSC) of service providers in 2000. ${ }^{22}$ The idea behind the NSC was to make services more accessible to ASMs, and hence key stakeholders were brought into one space, in what was called a "one-stop-shop" to provide all the required services (i.e. technical, managerial, financial, etc.). The NSC comprised multiple stakeholders, mostly expert organisations specialising in different aspects of the mining value chain and supporting activities. The committee also included finance institutions and investors who were keen to invest in ASM business operations. According to Mutemeri and Petersen, the NSC fund was earmarked for projects requiring capital investment of around R1million and upwards.

20 Minerals and Mining Policy of Republic of South Africa, 1998.

21 Dreschler (n 8); Department of Mineral Resources, Nurturing Junior Miners of the Future: A Strategic Framework to Facilitate the Growth of Small Scale Mining Sector in South Africa (December 2011).

22 Mutemeri, N. and Petersen, F.W (n 5) 287-288. 
As a pilot project, the government allocated a total of R15.1million, distributed among 20 small-scale mining projects. ${ }^{23}$ Assuming that the money was equally distributed, each project would have received about 755,000 rand. This money was to be used for purchasing equipment, providing rehabilitation guarantees, and to cover working capital until the operation breaks-even or becomes profitable. ${ }^{24}$ It is known that mining is a capitalintensive activity. The amount made available was unlikely to cover the capital needs until the operations became profitable.

Unfortunately, the NSC failed to produce economically viable projects. Most of the projects failed to repay the loans, resulting in millions of rand in funding being unrecovered. One of the funded projects remarked that its operation required a capital injection of R10 million, but becuase what was received was insufficient, it was forced to opt for second-hand equipment. Consequently, the project suffered breakdowns which continuously affected the profitability of the operation. For some, the main reason why their projects are still struggling is due to the lack of business and managerial skills. ${ }^{25}$ Faced with these disappointing results, the NSC was disbanded in October 2005 , having failed to deliver on its primary mandate.

A new structure, the Small-Scale Mining Board (SSMB) was established as a replacement to the NSC. Similarly, the SSMB comprised a number of expert-organisations, fewer in number than the NSC. A working structure was introduced, giving each organisation a defined role. With this new structure, ASM projects lodged (funding) applications via their regional offices rather than directly to the committee. But the problem of projects failing to repay the loans continued in this structure. As a result, the funding scheme was terminated towards the end of 2009. A total of 48 projects were funded through the programme across the country. As it stands, some projects have been abandoned, with some still operating on a hand-to-mouth basis. Those in existence are operating at subsistence levels. ${ }^{26}$ With the funding scheme discontinued, its services to ASMs are limited to non-financial support such as: establishment of a legal entity, guidance towards the identification of mineral deposits, environmental impact assessments, mining feasibility study

23 Solomons, I, "Artisanal, Small-Scale Mining Could Stimulate Huge Socioeconomic Benefits" (Mining Weekly, 17 July 2015).

24 Ledwaba (n 15) 114.

25 Ledwaba, P, Baseline Study on Artisanal and Small-Scale Mining in South Africa: Focus on the Free State and Mpumalanga Provinces. (Mintek. Internal report 2015).

26 Ledwaba (n 15) 114. 
and market study. ${ }^{27}$ There are also associated institutions such as Mintek, Council for Geosciences and the Mining Qualification Authority that offer services to ASMs; however, some of these services are provided at a cost, making them inaccessible to the miners.

Recall that the MPRDA recognises all forms of mining, whether small or large. Reverting to the White Paper, ASM was earmarked for small deposits which were deemed uneconomical by large-scale operations. It is through this notion that the provisions of the Act were founded. The MPRDA introduced a "special permit" to accommodate small-scale miners. Initially, a mining permit was granted on the basis that a mineral deposit can be exploited optimally within two years (five years total after renewal) and on an area extent of 1.5 hectares. Given the type of mineral deposits exploited by ASMs (over 70 per cent of them mine industrial minerals and these are usually large deposits); the provisions of the Act limit the growth of the sector. Furthermore, from an investment point of view, two years is not enough to develop profitable and sustainable mining operations.

As part of the 2008 MPRDA Amendments, the size extent was increased to five hectares. In the current Amendment Bill (MPRDA, 2013), it has been proposed that the duration be increased to a total of seven years after renewals. ${ }^{28}$ For some, this is still not enough to allow ASM operations to become profitable and sustainable.

Another amendment which came into effect on 8 December 2014 was tagged "One Environmental System". ${ }^{29}$ The decision for granting mining permits or any other mining license does not lie solely within the DMR, but also the Department of Environmental Affairs (DEA). According to the Act, "any person who wishes to apply to the Minister for a mining permit must simultaneously apply for environmental authorisation". ${ }^{30}$ This means that both the application for the permit (as per the MPRDA), and the Environmental Impact Assessment (EIA) application (as per NEMA) are to be lodged at the same time. This further means that the mining permit may only be issued in terms of the MPRDA once a NEMA Environmental Authorisation has been issued.

The enactment of NEMA Authorisations has added cost burdens, particularly to the already struggling ASMs. The application costs (which are

27 See Department of Mineral Resources website, <www.dmr.gov.za>

28 Mineral and Petroleum Resource Development Amendment Bill, 2013.

29 Department of Environmental Affairs (DEA), One Environmental System and the NEMA EIA 2014 Regulations (29 September 2015).

30 Minerals and Petroleum Resource Development Amendment Act, 2008. 
non-refundable) range between R2000 for a basic assessment to R10,000 for a full scoping report. ${ }^{31}$ In addition, these assessments can only be conducted by registered professionals who charge exorbitant fees. This works against the aspirant ASM and, hence, the future development of the sub-sector.

While the regulatory requirements are becoming stringent, the application system itself is not as friendly as it is ought to be. Applications for mining permits (and other mining licenses) are lodged using an online system. There have been increasing complaints from ASMs because they feel the system is too complicated and does not accommodate those who are previously disadvantaged..$^{32}$ The South African Mineral Resources Administrative System (SAMRAD) was introduced in 2011 with the aim of improving and speeding the application process. ${ }^{33}$ Even though the DMR does assist with the applications, the system has not been fully accepted because the majority are struggling to access this service as they are located far from DMR's regional offices.

Amid all these regulatory and administrative changes, things were relatively quiet between 2010 and 2014, especially after the funding scheme was discontinued. It was only towards the middle of 2015, following the appointment of a new Minister, that ASM was returned to the national agenda. The focus was on concerns raised by the communities and their views on the current interventions. ${ }^{34}$ The miners felt that the current interventions were inadequate to address their challenges.

In response to his findings, the Minister promised to collaborate with the Department of Small Business Development, which is a ministry dedicated to creating a conducive environment for the development and growth of small businesses and cooperatives through the provision of both financial and nonfinancial support services. Furthermore, a series of workshops were to be hosted and a platform given to ASMs to express their challenges and to also recommend potential solutions to be included in the future strategy for ASM in the country. These held in Northern Cape and KwaZulu-Natal provinces.

31 See Application for Environmental Authorisations in terms of National Environmental Management Act, 1998 as amended.

32 Community workshop on the application of mining permits held in Soutpan, Free State Province, South Africa (18 November 2014). Co-hosted by Mintek and the Department of Mineral Resources (DMR).

33 Creamer M, South African Mining Industry Sprinting Towards Positive Reform (Mining Weekly, 29 April 2011).

34 Minister Advocate Ngoako Ramatlhodi, Mineral Resource Department Budget Vote, 2015/16 (07 May 2015). 
Under the theme, "Optimising Small-Scale Mining Potential for Economic Growth and Development", relevant stakeholders convened to disseminate information, discuss challenges and propose solutions needed to develop the small-scale mining sector in South Africa.

The discussions at the two workshops were extensive, and as a recommendation, a resolution document was compiled and adopted by all stakeholders. The six pillars of the resolution talked to the following aspects: (1) Regulatory framework and support mechanisms; (2) Technical support mechanisms; (3) Access to funding for ASMs; (4) Access to local and international markets; (5) Promotion of women and youth in ASM; and (6) Implementation plan. ${ }^{35}$ At this point, the future of the sub-sector depended on this document. The sector is yet to see how the government will take the findings from the workshops forward. Notably, the government committed itself to developing a national framework for supporting small-scale miners taking into consideration the multiple challenges facing the sector.

\section{AMV AS A GUIDELINE TO ASM DEVELOPMENT}

The African Mining Vision is a shared vision supported by African governments to transform and build a well-governed and sustainable mining industry. With inputs from several regional, continental and global initiatives, particularly the Yaoundé Vision and the Mining Minerals and Sustainable Development (MMSD), AMV aims to create "a transparent, equitable and optimal exploitation of mineral resources to underpin broad-based sustainable growth and socio-economic development". ${ }^{36}$ On the premise of ASM, AMV supports the development of an industry that harnesses the potential of ASM to stimulate and contribute to local and national economies, improve livelihoods and advance integrated rural social and economic development.

The ASM sub-sector is recognised as a key development vehicle for rural communities submerged in poverty. In most developing countries, ASM activities started off as short-term solutions to provide livelihoods, but have since grown to contribute enormously to local and national economies. However, these positive contributions have been clouded by a myriad of negative consequences which have become the centre of attention for policy makers. AMV asserts that much as ASM has contributed positively, the subsector continues to be neglected at both international agendas and more

35 Small-Scale Mining Conference/Imbizo (Esikhaleni, Kwazulu-Natal, 27-28 August 2015).

36 African Mining Vision, 2009. 
importantly in local poverty alleviation strategies. This is despite ASM being recognised by most developing countries in Africa.

AMV attributes this to the negative impacts associated with ASM activities, and so, ASM continues to be trapped in the vicious cycle of poverty with very little growth, if any, and non-existent future prospects. The legal and regulatory failures on the part of government were identified by AMV as the main underlying cause. The continuous struggles to obtain security of tenure, to access mineral rights or even access to high-quality mineral resources is as a result of inadequate legal frameworks which are inclined more to the development of large-scale mining (LSM).

Pertinently, the AMV identifies the following challenges as being detrimental to the sector: poor understanding of specific needs of ASM; inadequate regulation and legal frameworks; lack of local infrastructure; lack of support for Research, Development and Innovation projects; and issues relating to technology and skills.

The AMV recommends, firstly as a foundation, an improvement in the understanding of ASM sector and how it speaks to a myriad of issues such as policy, regulation, environment, health and safety, economic, and societal issues. The top-down approach which has been used by many governments is criticised by the Vision. Governments need to move away from centralised, short-term and ad-hoc solutions that lack permanence. Governments need to invest in more pluralistic, holistic and multi-pronged approaches when dealing with ASM issues. There is also a need to broaden the approach to diversify ASM so as to link it to other alternative livelihood strategies to ensure future sustainability even after mining has ceased.

In all these recommendations, AMV strongly requests that they be done in direct consultation with ASM. It is crucial that ASM miners are involved in the planning, designing, implementation and evaluation of ASM initiatives. This will allow them to contribute to the initiatives, and ultimately own up to the failures and successes that result from them. In addition, the Yaoundé Vision proposed that funding schemes be established, market opportunities be opened, and the formalisation and organisation of ASMs and the provision of analytical and business related skills be perfected. This will help raise the profile of ASM and, hence, stimulate the interest of potential donors.

\section{LESSONS TO BE LEARNT}

The picture painted by the AMV, in terms of the issues and shortcomings, captures the situation in South Africa. Much as the ASM sub-sector is small in South Africa (relative to other countries); its potential cannot be overlooked. 
Given the current economic climate with LSM shedding jobs, government is particularly forced to seek alternative employment opportunities. This is increasingly important given the high unemployment rate in the country the official unemployment rate is recorded at 25.5 per cent, whereas the expanded unemployment rate which includes people who have stopped seeking employment is reported at a staggering 34.4 per cent. ${ }^{37}$

The lack of jobs is amongst the biggest challenges facing South Africa today. There is, therefore, a need to create job opportunities in order to alleviate poverty. Globally, ASM has been the catalyst for job creation employing 10 times more people than LSM. Hence, South Africa can use this platform to generate employment opportunities, particularly in rural areas where interventions are urgently required. The need to develop the ASM sub-sector in South Africa is of crucial importance. Moving forward, what can South Africa learn from its past experiences taking into cognisance the views and recommendations of the AMV?

Much as the AMV recognises the positive contributions of ASM, it also acknowledges the many problems facing the sub-sector, which need to be addressed before it can realise its full potential. AMV attributes the low success rate of ASM initiatives to the regulatory failures and impractical policies on the part of government. This is particularly correct in the case of South Africa. Even though the MPRDA recognises all forms of mining (ASM included), it does not take into account the specific needs and characteristics of ASM. As a result, it fails to accommodate the varied needs of artisanal, small-scale and junior miners. The MPRDA addresses only a portion of ASM activities, with those at the lower end of the spectrum functioning outside the legal framework. ${ }^{38}$ The MPRDA does not distinguish between ASM and LSM and hence subject them to the same legal requirements.

The finances, skills and capacity to meet and, to also comply with these regulatory requirements are beyond the capability of ASM. There is a need to reassess the legal framework to ensure that the entire ASM sub-sector is accommodated and catered for. This can only be done once the ASM subsector and its peculiar needs are well understood by policy makers.

Alongside this, there has been increasing concern and widespread acknowledgement of an escalating illegal mining industry in South Africa. "Zama-zamas" are miners that operate outside the regulatory framework, and usually target old, unused gold shafts in the Witwatersrand and Welkom

37 Statistics South Africa, Quarterly Labour Force Survey, 27 October 2015. 38 Debrah, A.A, Watson, I and Quansah (n 7). 
areas. More than 100 zama-zama incidents have been reported between 2008 and 2009, most of which have ended fatally. ${ }^{39}$ Like ASM, the biggest motivations for zama-zamas are the high unemployment and poverty rates in the country. ${ }^{40}$ The question posed is how different are the zama-zamas from ASM considering the circumstances from which they arise, nature of operations, lack of compliance, health and safety concerns, societal problems, etc.?

There are undisputed similarities between the two activities and, hence, there is a conflation between ASM and illegal mining. Like ASM, the zamazamas' activities are expected to grow because of few economic alternatives in the country. At present there are no reliable estimates of how much informal mining may be happening in South Africa, as well as no profile of what and where this is happening in the country. More so, there is no measure of the extent of these problems in South Africa currently.

As previously noted, general research on ASM in South Africa is limited. Very few studies have been conducted, so very little is known about the subsector. The AMV has argued that poor understanding of ASM activities, size and geographical distribution has precipitated these disappointing outcomes. In order to strengthen policy and assistance in the sub-sector, governments must establish, with greater precision, the number of people participating in ASM, their origins, demographics, and educational levels. ${ }^{41}$ One of the key challenges in South Africa is the lack of baseline information to inform ASM strategy of the country. This makes it difficult for government to monitor performance of interventions and to revise strategy and policy as necessary. A baseline study is required to determine the impact of ASM, and its links to the local economy.

The AMV, as well as its action plan, provides guiding principles for the development of ASM across the African continent. South Africa is yet to develop a strategy and its implementation plan founded on the AMV principles. The position of the ASM sub-sector in South Africa and to the entire mining industry is yet to be defined. With the majority of ASM exploiting IMs, the IM sector could potential be the "niche sector" for ASM in South Africa. IM deposits

39 Mining Weekly Online. 2009. SA Courts Now Recognise Illegal Mining as Organised Crime. <www.miningweekly.com/print-version/sa-courts-now-recognise-illegalmining-as-organised-crime-2009-11-13> accessed 8 October 2015.

40 Munakamwe, J, "The Interface Between the Legal and Illegal Mining Processes: Unpacking the Value Chain of Illegally Mined Gold" (10th GLU Conference, 30 September to 02 October 2015).

41 Hilson, D, Strengthening Artisanal Mining Research and Policy Through Baseline Census Activities (Natural Resources Forum, 2005). 
are, in most cases, found in close proximity of the surface making the mining process very simplistic. The beneficiation requirements of IMs are less demanding. There is also a significant market locally for IMs in South Africa. This is an avenue worth investigating - it has the potential to strategically position ASM in the mining industry.

Currently, the future of ASM in South Africa lies in the resolution document which was adopted by all relevant stakeholders, including the ASM communities. In the document, the government committed itself to developing a national framework which will guide the development of the sub-sector, and also supporting mechanisms necessary to advance the sub-sector. What should follow next is the implementation plan of how ASM will be supported taking into account past failures in addressing the following challenges: access to mineral rights and security of tenure, lack of finance, poor or no marketing strategies, lack of appropriate skills, and compliance-related issues. This should be accompanied by the allocation of resources (finance and capacity) for implementation. Part of the reasons for the failure of ASM projects was the inadequate funding to carry out these projects, which compromised their success. It is crucial that projects receive adequate funding and are wellcapacitated, collaboration between key players is paramount in this regard.

\section{CONCLUDING REMARKS: WHY POLICY HAS FAILED}

The South African mining legislation has evolved in an attempt to make the mining industry more accessible to the previously disadvantaged. The recognition of the ASM sub-sector was one way to remedy the past injustices from the Apartheid regime. In the two decades of promoting ASM, South Africa managed to do several things right.

Firstly, the acknowledgement of ASM by the main legislative framework was a step in the right direction. However, the legislation failed to distinguish between ASM and LSM, and this resulted in negative ripple effects to the subsector. Failure to differentiate between the two forms of mining meant that treatment and expectations from government and supporting organisations would be the same. As it stands, ASMs are subjected to the same regulatory requirements as LSMs. On the part of government, this was done as a risk management strategy to safeguard against the deleterious effects of ASM on safety, health and environment. Understandably so, it is still argued that the historical, economic, developmental and social backgrounds and situations of ASM necessitate the need for special treatment. This blanket approach has left loopholes in policy such that an average small-scale miner would not be 
able to meet the minimum criteria.

Secondly, introducing a "special permit" for small-scale miners as a way of accommodating them in the industry was a good initiative. This was meant to be an affordable and simplified option for them. Unfortunately, the opposite is true in the sense that this "special permit" is not "easy and affordable" to the targeted group. Some of the MPRDA requirements act as a restriction to small-scale miners due to the amount of capital that is necessary to complete them. Two major examples of these is the pre-feasibility study which often requires the drilling of boreholes, and the environmental impact assessment which can only be done by professionals with high consulting fees. The recent approval of the "one environmental system" has further added to the financial burden of aspirant ASMs. As a result, the landscape of ASM in South Africa is rapidly changing - ASM is no longer for the poor, disadvantaged individuals but for those with deep pockets.

In addition, the administrative processes are deemed complex, demanding and slow. The online system is a barrier for most small-scale miners. Knowingly, the majority of aspirant small-scale miners are from rural areas where infrastructure is inadequate. Access to computers and the internet, and also the fact that payment can only be made through an electronic payment are some of the frustrations.

The provisions of the permit also present barriers even to those that managed to acquire them. The size extent and the total duration for mining permits limit growth in the sub-sector. Most ASM operations find themselves in a situation where they cannot secure funding because the payback period does not make sense, they fail to secure long-term market contracts because they can only operate for a few years, and they fail to invest back into their businesses because there are few growth prospects.

In terms of capacity, the Small-Scale Mining Directorate that is housed in the DMR has limited capacity not only to deal with permitting small- scale mines but also is under resourced to monitor and evaluate ASM activities in South Africa as a whole. Although there are initiatives that have been undertaken by the DMR to engage with small-scale miners at the grassroots level, there still seems to be a lack of understanding of the unique needs of ASM by the department.

The informal and often illegal nature of ASM requires innovative approaches to monitoring and evaluation. It is very different from largescale mining and cannot be treated the same.

To conclude, the policy is not working because it does not speak to the needs of the ASM sub-sector. South Africa has, over the years, used an umbrella approach in addressing ASM-related issues. The problems faced by ASMs 
tend to be similar at a strategic level, but experience has shown that the deep social, cultural and developmental settings of a country/area have a great influence on what is called "common problems". It is, therefore, important for South Africa to have a proper and holistic understanding of the nature of ASM. Taking into account the recommendations of the AMV, firstly as a foundation, South Africa should invest in a proper study to understand the nature of ASM and how it speaks to issues such as policy, regulation, environment, health and safety, economic, and societal issues. Secondly, government needs to invest in resources and building capacity on its part, to deliver on the objectives or milestones set for the ASM sub-sector. 